\title{
The TransFLUas influenza transmission study in acute healthcare - recruitment rates and protocol adherence in healthcare workers and inpatients
}

Hila Schwarz ${ }^{1}$, Jürg Böni' ${ }^{2}$ Roger D. Kouyos ${ }^{1}$, Teja Turk ${ }^{1,2}$, Edouard Battegay ${ }^{3}$, Malcolm Kohler ${ }^{4}$, Rouven Müller ${ }^{5}$, Heidi Petry ${ }^{6}$, Hugo Sax ${ }^{1}$, Rainer Weber ${ }^{1}$, Allison McGeer ${ }^{7}$, Alexandra Trkola ${ }^{2+}$ and Stefan P. Kuster ${ }^{1 *+}$ (D)

\begin{abstract}
Background: Detailed knowledge about viral respiratory disease transmission dynamics within healthcare institutions is essential for effective infection control policy and practice. In the quest to study viral transmission pathways, we aimed to investigate recruitment rates and adherence of healthcare workers (HCWs) and hospital inpatients with a study protocol that involves prospective surveillance based on daily mid-turbinate nasal swabs and illness diaries.

Methods: Single center prospective surveillance of patients and HCWs in three different hospital departments of a tertiary care center during an entire influenza season in Switzerland. Inpatients and acute care HCWs were asked to provide mid-turbinate nasal swabs and illness diaries on a daily basis. Study protocol adherence and recruitment rates were the primary outcomes of interest.

Results: A total 251 participants (59 (23.5\%) health care workers and 192 (76.5\%) inpatients) were recruited from three different hospital wards. Recruitment rates differed between HCWs (62.1\% of eligible HCWs) and inpatients (32.5\%; $P<0.001)$, but not within HCWs $(P=0.185)$ or inpatients $(P=0.301)$ of the three departments. The total number of study-days was 7874; 2321 (29.5\%) for inpatients and 5553 (70.5\%) for HCWs. HCWs were followed for a median of 96 days (range, 71-96 days) and inpatients for 8 days (range, 3-77 days). HCWs provided swabs on 73\% (range, 0-100\%) of study days, and diaries on 77\% (range 0-100\%). Inpatients provided swabs and diaries for 83\% (range, 0-100\%) of days in hospital. In HCWs, increasing age, working in internal medicine and longer duration of total study participation were positively associated with the proportion of swabs and diaries collected. Adherence to the study protocol was significantly lower in physicians as compared to nurses for both swabs $(P=0.042)$ and diaries $(P=0.033)$. In inpatients, no association between demographic factors and adherence was detected.

Conclusions Prospective surveillance of respiratory viral disease was feasible in a cohort of inpatients and HCWs over an entire influenza season, both in terms of recruitment rates and adherence to a study protocol that included daily specimen collection and illness diaries.
\end{abstract}

Trial registration: clinicaltrials.gov NCT02478905. Date of registration June 23, 2015.

Keywords: Influenza, Transmission, Asymptomatic infection, Surveillance, Healthcare-associated infection

\footnotetext{
*Correspondence: stefan.kuster@usz.ch

${ }^{\dagger}$ Alexandra Trkola and Stefan P. Kuster contributed equally to this work.

'Division of Infectious Diseases and Hospital Epidemiology, University

Hospital and University of Zurich, Raemistrasse 100 / HAL14 D6, 8091 Zürich,

Switzerland

Full list of author information is available at the end of the article
}

(c) The Author(s). 2019 Open Access This article is distributed under the terms of the Creative Commons Attribution 4.0 International License (http://creativecommons.org/licenses/by/4.0/), which permits unrestricted use, distribution, and reproduction in any medium, provided you give appropriate credit to the original author(s) and the source, provide a link to the Creative Commons license, and indicate if changes were made. The Creative Commons Public Domain Dedication waiver (http://creativecommons.org/publicdomain/zero/1.0/) applies to the data made available in this article, unless otherwise stated. 


\section{Background}

Influenza remains the most common infectious disease cause of death in the developed world, causing up to $5^{\prime}$ 000 hospitalizations and 1'500 deaths in Switzerland annually [1]. Elderly persons, young children and persons with underlying medical conditions are at highest risk for adverse outcomes [2]. Despite barrier protection measures and vaccination campaigns among healthcare workers (HCWs), nosocomial acquisition of influenza is a well-known patient safety issue, and outbreaks of influenza are common in both acute and long-term care [3-8].

The epidemiology and transmission dynamics of influenza in hospitals, however, are poorly understood. In particular, it is not known how often asymptomatic or minimally symptomatic persons may transmit disease $[9,10]$. This poses a problem because one-in-three influenza infections are thought to be asymptomatic [11]. If asymptomatic persons transmit influenza, vaccination of patients and HCWs before start of the influenza season, the permanent use of masks by HCWs during influenza season, and quarantine for previously exposed inpatients may be the only available measures to reduce the number of influenza transmission events in acute care hospitals [12-14]. Bridging this knowledge gap would be of major benefit to infection prevention and control recommendations, and may result in reduced morbidity and mortality associated with influenza in hospitals. Studying the question whether asymptomatic individuals transmit influenza virus in acute care, however, requires close monitoring of a tight group of HCWs and patients with a high participation rate and adherence to a study protocol that comprises close monitoring of disease activity, symptoms and contacts between individuals.

To define whether exposure to asymptomatic subjects with influenza infection constitutes a risk for influenza virus transmission in an acute care hospital setting, we designed the TransFLUas study, an active, prospective surveillance study of HCWs and inpatients. We collected mid-turbinate nasal swabs and influenza-like illness symptom diaries on a daily basis on dedicated study wards over an entire influenza season, with the goal to assess influenza transmission pathways in relation to influenza symptoms. In this report, we describe participant recruitment and adherence to the protocol during the 2015/2016 influenza season.

\section{Methods}

\section{Study setting, design and procedures}

We performed a single center prospective surveillance study of HCWs and inpatients in three different hospital units (pulmonology, hematology and internal medicine) at the University Hospital Zurich over the 2015/2016 influenza season. The University Hospital Zurich is a 900 beds university-affiliated tertiary care center that covers all specialties except orthopedic surgery and pediatrics. It serves a population of $400^{\prime} 000$ inhabitants for primary and 1'443'000 for tertiary care [15].

We followed patients in these 3 units, as well as nursing staff (nurses and assistant nurses), corporate hospitality staff with direct patient contact and medical staff (attending physicians and those in training) working on the same wards during the influenza season. Influenza season was considered to start when Swiss national sentinel surveillance levels exceeded the national threshold for an influenza epidemic and ended when influenza levels fell below the epidemic threshold for two consecutive weeks. (https://www.bag.admin.ch/bag/de/home/ krankheiten/ausbrueche-epidemien-pandemien/aktuelleausbrueche-epidemien/saisonale-grippe---lagebericht-sch weiz.html). All HCWs and inpatients $\geq 18$ years of age on the ward under surveillance were eligible for the study. HCWs were excluded if they planned to spend more than two consecutive weeks outside of Switzerland during the influenza season in order to secure consistency over time. HCWs were recruited by study personnel at staff meetings prior to the influenza season. Patients were approached by study personnel upon admission to the participating study ward. Patients who were not competent to consent were excluded. Participants were not compensated for study participation.

HCWs were asked to complete a baseline demographic questionnaire, asking about personal data (age, sex), household characteristics that may be associated with reduced (e.g. having received seasonal influenza vaccine, influenza vaccination history) or increased (e.g. household crowding index (defined as the number of people per household divided by the number of bedrooms), living with children in their household) risk of influenza, and underlying medical conditions (Charlson comorbidity index) and long-term medication [16]. A questionnaire was filled in for inpatients upon enrollment, covering baseline characteristics, including age, sex, date of admission, vaccination status and co-morbidities (Charlson comorbidity index). Length of hospital stay was calculated from discharge and admission dates after hospital discharge.

In consenting inpatients, study nurses collected mid-turbinate nasal swabs daily from the day of enrollment until discharge and filled in diaries covering signs and symptoms of influenza infection (including cough, sore throat, fever $\geq 38.0^{\circ} \mathrm{C}$, nasal congestion, weakness, headache, loss of appetite or myalgia) and contacts with other subjects with influenza symptoms. Patients were asked to self-collect swabs and fill in daily diaries for 2 days after discharge and send the items back to the study office. HCWs were asked to self-collect mid-turbinate nasal swabs and to fill in the illness diaries on a 
daily basis (including days off work) and drop the items in an inbox placed on each study ward. The self-collection of flocked mid-turbinate nasal swabs has been shown to be comparable to nasopharyngeal aspirates in children and adults [17-19]. Updates on the current status of the influenza epidemic and reminders to continue sending in swabs and diaries were sent to participating HCWs by email each week.

\section{Definitions}

Recruitment rate was defined as the number of consenting individuals divided by the number of eligible HCWs and inpatients, respectively.

We defined adherence with the study protocol for each study participant as the number of swabs and illness diaries, respectively, that were submitted in relation to the number of samples/diary entries that the study participant was expected to submit based on the study protocol.

\section{Statistical analysis}

Categorical data were tested for differences using Fisher exact tests, whereas continuous variables were tested using Wilcoxon rank sum tests or the Student's t test, as appropriate. Multivariable linear regression analysis was used to determine predictors for adherence to the study protocol. Potential predictors among participant characteristics were considered for inclusion in multivariable models based on clinical judgment and previous hypotheses, with final models representing those that best balanced parsimony and fit. Data were analysed using Stata ${ }^{\circ}$ version 13.1 (Stata Corporation, College Station, TX). Two-tailed $P$-values $<0.05$ were considered statistically significant.

\section{Results}

\section{Recruitment}

In total, 251 participants, including 59 (23.5\%) HCWs and $192(76.5 \%)$ inpatients were enrolled in the study. Overall, 192 out of 591 (32.5\%) eligible patients could be recruited, and 59/95 (62.1\%) HCWs participated in the study $(P<0.001)$ (see Table 1$)$. Recruitment rates did not differ between the three departments for either HCWs or inpatients.

\section{Healthcare worker and patient characteristics}

HCWs and patient characteristics are shown in Tables 2 and 3 , respectively. HCWs had a median age of 30.5 (range, 18.0-58.0) years and 50 (84.7\%) were female. The median household crowding index was 1.3 (range, $0.5-3)$, and $11(18.6 \%)$ had children $<18$ years of age in their household. There were no significant differences in demographic or other characteristics between HCWs from the three different study wards.
We enrolled 192 patients with a median age of 57.9 years (range, 18.3-94.1), and an overall median Charlson comorbidity index of 2 (range 0-8) (Table 3). Patients from the internal medicine ward were older than others and more likely to have peripheral vascular disease or diabetes, whereas patients with chronic pulmonary disease were more likely to be hospitalized on the pulmonology ward and patients with leukemia were almost exclusively admitted to the hematology ward.

\section{Adherence to the study protocol}

Table 4 shows the adherence to the study measures in HCWs and inpatients. In total, 7874 study-days were recorded, 2321 (29.5\%) for inpatients and 5553 (70.5\%) for HCWs. The median number of study-days was 96 (range, 71-96) for HCWs and 8 (range, 3-77) for inpatients. The median number of HCW- or patient-days did not differ between the study wards.

A total of 1469 mid-turbinate nasal swabs (median, 5; range, 0-68) were collected from participating inpatients, 1430 (97.3\%) during hospitalization (median, 4; range, $0-68)$ and $39(2.7 \%)$ after discharge. Twentyseven (14.1\%) inpatients provided swabs after hospital discharge. The median percentage of eligible swabs submitted per day in hospital was $83 \%$ (range, $0-100 \%$ ) and did not differ between the three study wards. There was no association of adherence to the study protocol with age, sex, underlying comorbidities, ward or duration of participation in the study (data not shown).

HCWs self-collected a total of 3513 swabs (median, 69; range, 0-96). The median proportion of swabs per day in study among HCWs was 73\% (range, 0-100\%) and of diaries $77 \%$ (range $0-100 \%$ ). Multivariable linear regression analysis revealed increasing age $(P=0.001)$, working in internal medicine as compared to pulmonology $(P=0.019)$ and longer duration of total study participation to be positively associated with the proportion of swabs collected. The same predictors were found for adherence with filling in study diaries (data not shown). Adherence to the study protocol was significantly lower in physicians as compared to nurses for both collecting swabs (median number of swabs per day: 46\% (range, $0-96 \%$ ) in physicians vs. $78 \%$ (range, $0-100 \%$ ) in nurses, $P=0.042$ ) and study diaries (median number of diaries per day: $47 \%$ (range, $0-97 \%$ ) in physicians vs. $81 \%$ (range, $0-100 \%$ ) in nurses, $P=0.033$ ).

Figure 1 depicts the total number of swabs and diaries collected in HCWs (panel A) and inpatients (panel B) per calendar week. Given that the number of enrolled HCWs was stable over time, a marked decrease in the number of swabs and diaries could be detected after 9 weeks of study data collection, reflecting a decrease in protocol adherence. In hospitalized patients, however, such a decreasing trend in the number of samples was not observed. 
Table 1 Recruitment rates of patients and healthcare workers enrolled in prospective surveillance of influenza infection, University Hospital Zurich, 2015/2016 influenza season

\begin{tabular}{|c|c|c|c|c|c|}
\hline \multirow[t]{2}{*}{ Participants } & \multicolumn{4}{|l|}{ Department } & \multirow[b]{2}{*}{$P$-value } \\
\hline & All departments & Pulmonology & Hematology & Internal medicine & \\
\hline Patients & 192/591 (32) & $80 / 263(30)$ & $56 / 179(31)$ & $56 / 149(38)$ & 0.3 \\
\hline HCWs & $59 / 95(62)$ & 19/33 (52) & 17/33 (58) & $22 / 29(76)$ & 0.18 \\
\hline Nurses & 49 & 15 & 13 & 21 & \\
\hline Physicians ${ }^{1}$ & 9 & 3 & 4 & 1 & \\
\hline Other HCWs ${ }^{2}$ & 1 & 1 & 0 & 0 & \\
\hline
\end{tabular}

Data are $\mathrm{n}(\%) .{ }^{1}$ one HCW was working on all three wards. ${ }^{2}$ one HCW from corporate hospitality

Abbreviations: HCWs healthcare workers

Table 2 Healthcare worker characteristics on wards with active surveillance for influenza, University Hospital Zurich, 2015/16 influenza season

\begin{tabular}{|c|c|c|c|c|c|}
\hline \multirow[t]{2}{*}{ Characteristic } & \multicolumn{4}{|l|}{ Department } & \multirow[b]{2}{*}{$P$-value } \\
\hline & $\begin{array}{l}\text { All departments } \\
(n=59)^{1}\end{array}$ & $\begin{array}{l}\text { Pulmonology } \\
(n=17)\end{array}$ & $\begin{array}{l}\text { Hematology } \\
(n=19)\end{array}$ & $\begin{array}{l}\text { Internal medicine } \\
(n=22)\end{array}$ & \\
\hline Age, years, median (range) & $30.5(18.0-58.0)$ & $30.5(18.5-51.6)$ & $31.1(21.5-58.0)$ & $26.7(18.0-51.9)$ & 0.52 \\
\hline Female sex & $50(84.7)$ & $14(82.4)$ & $17(89.5)$ & $19(86.4)$ & 0.45 \\
\hline \multicolumn{6}{|l|}{ Profession } \\
\hline Nurse & $49(83.1)$ & $13(76.5)$ & $15(79.0)$ & $21(95.5)$ & \multirow[t]{3}{*}{0.27} \\
\hline Physician & $9(15.3)$ & $3(17.7)$ & $4(21.1)$ & $1(4.6)$ & \\
\hline Other & $1(1.7)$ & $1(5.9)$ & $0(0)$ & $0(0)$ & \\
\hline Charlson comorbidity index, median (range) & $0(0-1)$ & $0(0-1)$ & $0(0-0)$ & $0(0-1)$ & 0.88 \\
\hline Myocardial infarction & $0(0)$ & $0(0)$ & $0(0)$ & $0(0)$ & n.a. \\
\hline Congestive cardiac insufficiency & $0(0)$ & $0(0)$ & $0(0)$ & $0(0)$ & n.a. \\
\hline Peripheral vascular disease & $0(0)$ & $0(0)$ & $0(0)$ & $0(0)$ & n.a. \\
\hline Chronic pulmonary disease & $2(3.4)$ & $1(5.9)$ & $0(0)$ & $1(4.6)$ & 0.59 \\
\hline Conjuctive tissue disease & $0(0)$ & $0(0)$ & $0(0)$ & $0(0)$ & n.a. \\
\hline Diabetes without complications & $0(0)$ & $0(0)$ & $0(0)$ & $0(0)$ & n.a. \\
\hline Peptic ulcer disease & $1(1.7)$ & $0(0)$ & $0(0)$ & $1(4.6)$ & 0.44 \\
\hline Chronic disease of the liver or cirrhosis & $0(0)$ & $0(0)$ & $0(0)$ & $0(0)$ & n.a. \\
\hline Hemiplegia & $0(0)$ & $0(0)$ & $0(0)$ & $0(0)$ & n.a. \\
\hline Moderate or severe kidney disease & $0(0)$ & $0(0)$ & $0(0)$ & $0(0)$ & n.a. \\
\hline Diabetes with chronic complications & $0(0)$ & $0(0)$ & $0(0)$ & $0(0)$ & n.a. \\
\hline Solid organ malignancy & $0(0)$ & $0(0)$ & $0(0)$ & $0(0)$ & n.a \\
\hline Leukemia & $0(0)$ & $0(0)$ & $0(0)$ & $0(0)$ & n.a. \\
\hline Lymphoma & $0(0)$ & $0(0)$ & $0(0)$ & $0(0)$ & n.a. \\
\hline Moderate or severe liver disease & $0(0)$ & $0(0)$ & $0(0)$ & $0(0)$ & n.a. \\
\hline Malignant tumor, metastasis & $0(0)$ & $0(0)$ & $0(0)$ & $0(0)$ & n.a. \\
\hline AIDS & $0(0)$ & $0(0)$ & $0(0)$ & $0(0)$ & n.a. \\
\hline Dementia & $0(0)$ & $0(0)$ & $0(0)$ & $0(0)$ & n.a. \\
\hline Household crowding index, median (range) & $1.3(0.5-3)$ & $1.3(1-2.5)$ & $1.3(1-2)$ & $1.3(0.5-3)$ & 0.99 \\
\hline Children (< 18 years) in household & $11(18.6)$ & $5(22.7)$ & $1(5.3)$ & $5(22.7)$ & 0.24 \\
\hline
\end{tabular}

Data are $\mathrm{n}(\%)$, unless indicated otherwise. ${ }^{1}$ Sum of HCWs of different departments does not equal total number as one HCW worked on all wards and thus was not assigned to one single department 
Table 3 Patient characteristics

\begin{tabular}{|c|c|c|c|c|c|}
\hline \multirow[t]{2}{*}{ Characteristic } & \multicolumn{4}{|l|}{ Department } & \multirow[b]{2}{*}{$P$-value } \\
\hline & $\begin{array}{l}\text { All departments } \\
(n=192)\end{array}$ & $\begin{array}{l}\text { Pulmonology } \\
(n=80)\end{array}$ & $\begin{array}{l}\text { Hematology } \\
(n=56)\end{array}$ & $\begin{array}{l}\text { Internal medicine } \\
(n=56)\end{array}$ & \\
\hline Age, years, median (range) & $57.9(18.3-94.1)$ & $54.6(18.3-79.5)$ & $55.9(21.0-87.6)$ & $62.2(29.4-94.2)$ & 0.002 \\
\hline Female sex & $80(41.6)$ & $32(40)$ & $25(44.6)$ & $23(41)$ & 0.86 \\
\hline Charlson comorbidity index, median (range) & $2(0-8)$ & $1(0-8)$ & $2(0-6)$ & $2(0-7)$ & 0.15 \\
\hline Myocardial infarction & $10(5.2)$ & $3(3.7)$ & $3(5.4)$ & $4(7.1)$ & 0.71 \\
\hline Congestive cardiac insufficiency & $16(8.3)$ & $7(8.7)$ & $1(1.8)$ & $8(14.2)$ & 0.13 \\
\hline Peripheral vascular disease & $12(6.2)$ & $2(2.5)$ & $1(1.8)$ & $9(16)$ & 0.006 \\
\hline Chronic pulmonary disease & $78(40.6)$ & $64(80)$ & $5(8.9)$ & $9(16)$ & $<0.001$ \\
\hline Conjuctive tissue disease & 0 & 0 & 0 & 0 & n.a \\
\hline Diabetes without complications & $27(14)$ & $11(13.7)$ & $2(3.6)$ & $14(25)$ & 0.017 \\
\hline Peptic ulcer disease & $2(1)$ & $1(1.2)$ & 0 & $1(1.8)$ & 0.50 \\
\hline Chronic disease of the liver or cirrhosis & $3(1.6)$ & 0 & 0 & $3(5.4)$ & 0.07 \\
\hline Hemiplegia & $2(1)$ & $1(1.2)$ & 0 & $1(1.8)$ & 0.67 \\
\hline Moderate or severe kidney disease & $22(11.5)$ & $11(13.7)$ & $4(7.1)$ & $7(12.5)$ & 0.47 \\
\hline Diabetes with chronic complications & $6(3.1)$ & $1(1.2)$ & 0 & $5(8.9)$ & 0.035 \\
\hline Solid organ malignancy & $12(6.2)$ & $4(5)$ & $1(1.8)$ & $7(12.5)$ & 0.054 \\
\hline Leukemia & $20(10.4)$ & $1(1.2)$ & 19 (33.9) & 0 & $<0.001$ \\
\hline Lymphoma & $7(3.6)$ & $1(1.2)$ & $5(8.9)$ & $1(1.8)$ & 0.10 \\
\hline Moderate or severe liver disease & $16(8.3)$ & $7(8.7)$ & $4(7.1)$ & $5(8.9)$ & 0.81 \\
\hline Malignant tumor, metastasis & $5(2.6)$ & $4(5)$ & 0 & $1(1.8)$ & 0.30 \\
\hline AIDS & $2(1)$ & 0 & $1(1.8)$ & $1(1.8)$ & 0.49 \\
\hline Dementia & $1(0.5)$ & $1(1.2)$ & 0 & 0 & 0.59 \\
\hline
\end{tabular}

Data are $\mathrm{n}(\%)$, unless indicated otherwise

Abbreviations: n.a. not applicable, AIDS acquired immunodeficiency syndrome

\section{Discussion}

In a prospective surveillance study of asymptomatic and symptomatic influenza infection conducted on three wards of a large university hospital during the influenza season $2015 / 2016$, we were able to recruit $32 \%$ of inpatients and $62 \%$ of HCWs. HCWs provided self-collected swabs on $73 \%$ of all study days and illness diaries on $77 \%$, whereas swabs and diaries could be obtained from inpatients in $83 \%$ of hospital days. Adherence to the study protocol after discharge was poor in hospitalized patients. Physicians provided a lesser proportion of swabs and diaries than nurses, and higher age, working in internal medicine and longer duration of participation were associated with better adherence among HCWs. Whereas the total self-collected swabs and diaries decreased over time in $\mathrm{HCWs}$, adherence to the protocol was stable over time in hospitalized patients.

We were unable to locate any other study that followed cohorts of inpatients and HCWs on dedicated wards over one influenza season with the request to provide nasal swabs and diaries routinely irrespective of symptoms. Although our design is unique, we consider adherence to both illness diaries and swabs in more than
$75 \%$ of study-days satisfying, which is supported by other authors who suggest to aim for response rates of at least $60 \%$ in surveys performed on a single point in time [20]. The high coverage in daily swabs and diaries highlights that, even considering decrease in adherence amongst $\mathrm{HCW}$ observed in later study periods, the majority of shedders must have been captured as influenza symptoms and viral shedding usually last more than a single day [21].

Although the problem of non-adherence in clinical trials is quite common for multiple reasons, [22] it can be improved by focusing on protocols and processes, even if they seem peripheral [23]. Frost et al. emphasize the importance of favorable trial conditions and organizational context, which can influence the quality of diary data collected [24]. We believe that daily presence of our study team on study wards together with a simple diary and high motivation of participating HCWs helped to achieve high adherence rates in our study despite its long duration. One other favorable factor may be the staffing conditions in our institution. It has a relatively high number of physicians and nurses per 100 hospitalizations compared to other institutions in our 
Table 4 Adherence to study requirements (collection of swabs and diaries on a daily basis) of patients and healthcare worker enrolled in prospective surveillance of influenza infection, 2015/2016 influenza season

\begin{tabular}{|c|c|c|c|c|c|}
\hline & \multicolumn{4}{|l|}{ Department } & \multirow[b]{2}{*}{$P$-value } \\
\hline & All departments & Pulmonology & Hematology & Internal Medicine & \\
\hline \multicolumn{6}{|l|}{ Days in study } \\
\hline Total patients & 2321 & 920 & 788 & 613 & n.a. \\
\hline Median days in study per patient, range & $8(3-77)$ & $9(3-77)$ & $8(3-65)$ & $8(3-34)$ & 0.83 \\
\hline Total HCWs & 5553 & 1587 & 1774 & 2096 & n.a \\
\hline Median days in study per HCW, range & $96(71-96)$ & $96(71-96)$ & $96(79-96)$ & $96(80-96)$ & 0.45 \\
\hline Nurses & 96 (93-96) & $96(94-96)$ & $96(93-96)$ & $96(96-96)$ & 0.91 \\
\hline Physicians & $82(71-96)$ & $82(71-92)$ & $85(79-88)$ & $80(80-80)$ & 0.79 \\
\hline \multicolumn{6}{|l|}{ Swabs } \\
\hline \multicolumn{6}{|l|}{ Patients } \\
\hline Total number of swabs in study & 1469 & 592 & 471 & 406 & n.a. \\
\hline Median number of swabs per patient, range & $5(0-68)$ & $4.5(0-68)$ & $5(0-49)$ & $5(0-26)$ & 0.84 \\
\hline Total number of swabs in hospital & 1430 & 568 & 461 & 401 & n.a. \\
\hline Median number of swabs abs in hospital, range & $4(0-68)$ & $4(0-68)$ & $5(0-49)$ & $5(0-26)$ & 0.73 \\
\hline Total number of swabs after discharge & 39 & 24 & 10 & 5 & n.a. \\
\hline Median number of swabs after discharge, range & $0(0-4)$ & $0(0-4)$ & $0(0-3)$ & $0(0-2)$ & 0.53 \\
\hline Swabs per day in study, $\%$ & $60(0-100)$ & $60(0-100)$ & $60(0-100)$ & $60(0-90)$ & 0.86 \\
\hline Swabs per day in hospital, $\%$ & $83(0-100)$ & $80(0-100)$ & $84(0-100)$ & $85(0-100)$ & 0.97 \\
\hline \multicolumn{6}{|l|}{ HCWs } \\
\hline Total number of swabs in study & 3513 & 787 & 1244 & 1390 & n.a \\
\hline Median number of swabs in study, range & $69(0-96)$ & $42(0-96)$ & $69(18-96)$ & $77.5(0-92)$ & 0.29 \\
\hline Swabs per day in study, $\%$ & $62(0-100)$ & $49(0-100)$ & $70(20-100)$ & $66(0-96)$ & 0.26 \\
\hline \multicolumn{6}{|l|}{ Nurses } \\
\hline Total number of swabs in study & 3150 & 694 & 1066 & 1390 & n.a \\
\hline Median number of swabs in study, range & $75(0-96)$ & $65(0-96)$ & $71(22-96)$ & $78(8-92)$ & 0.56 \\
\hline Swabs per day in study, $\%$ & $67(0-100)$ & $56(0-100)$ & $74(23-100)$ & $69(8-96)$ & 0.56 \\
\hline \multicolumn{6}{|l|}{ Physicians } \\
\hline Total number of swabs in study & 339 & 69 & 178 & 0 & n.a \\
\hline Median number of swabs in study, range & $36(0-92)$ & $27(0-42)$ & $48.5(18-63)$ & 0 & 0.25 \\
\hline Swabs per day in study, $\%$ & $43(0-96)$ & $26(0-46)$ & $53(20-74)$ & 0 & 0.25 \\
\hline \multicolumn{6}{|l|}{ Diaries } \\
\hline \multicolumn{6}{|l|}{ Patients } \\
\hline Total number of diaries in study & 1470 & 593 & 471 & 406 & n.a. \\
\hline Median number of diaries in study, range & $5(0-68)$ & $4.5(0-68)$ & $5(0-49)$ & $5(0-26)$ & 0.85 \\
\hline Total number of diaries in hospital, total & 1431 & 569 & 461 & 401 & n.a \\
\hline Median number of diaries in hospital, range & $4(0-68)$ & $4(0-68)$ & $(0-49)$ & $5(0-26)$ & 0.75 \\
\hline Total number of diaries after discharge, total & 39 & 24 & 10 & 5 & n.a \\
\hline Median number of diaries after discharge, range & $0(0-4)$ & $0(0-4)$ & $0(0-3)$ & $0(0-2)$ & 53 \\
\hline Diaries per day in study, $\%$ & $60(0-100)$ & $60(0-100)$ & $60(0-100)$ & $60(0-90)$ & 0.86 \\
\hline Diaries per day in hospital, \% & $83(0-100)$ & $80(0-100)$ & $84(0-100)$ & $85(0-100)$ & 0.97 \\
\hline \multicolumn{6}{|l|}{ HCWs } \\
\hline Total number of diaries in study & 3661 & 849 & 1275 & 1444 & n.a. \\
\hline Median number of diaries in study, range & $72(0-96)$ & $49(0-96)$ & $72(18-96)$ & $83(0-94)$ & 0.30 \\
\hline Diaries per day in study, $\%$ & $77(0-100)$ & $53(0-100)$ & $77(20-100)$ & $86(0-98)$ & 0.27 \\
\hline
\end{tabular}


Table 4 Adherence to study requirements (collection of swabs and diaries on a daily basis) of patients and healthcare worker enrolled in prospective surveillance of influenza infection, 2015/2016 influenza season (Continued)

\begin{tabular}{|c|c|c|c|c|c|}
\hline & \multicolumn{4}{|l|}{ Department } & \multirow[b]{2}{*}{$P$-value } \\
\hline & All departments & Pulmonology & Hematology & Internal Medicine & \\
\hline \multicolumn{6}{|l|}{ Nurses } \\
\hline Total number of diaries in study & 3275 & 740 & 1091 & 1444 & n.a \\
\hline Median number of diaries in study, range & $78(0-96)$ & $69(0-96)$ & $75(24-96)$ & $83(8-94)$ & 0.59 \\
\hline Diaries per day in study, $\%$ & $81(0-100)$ & $73(0-100)$ & $78(25-100)$ & $86(8-98)$ & 0.57 \\
\hline \multicolumn{6}{|l|}{ Physicians } \\
\hline Total number of diaries in study & 361 & 84 & 184 & 0 & n.a \\
\hline Median number of diaries in study, range & $37(0-93)$ & $35(0-49)$ & $49(18-68)$ & 0 & 0.25 \\
\hline Diaries per day in study, $\%$ & $47(0-97)$ & $43(0-53)$ & $60(20-77)$ & 0 & 0.25 \\
\hline
\end{tabular}

Abbreviations: n.a. not applicable, HCWs healthcare workers

country, [25] and, as a university hospital, is experienced with clinical studies. The Swiss health system belongs to the five highest ranked countries with regard to personal health care access and quality, [26] which may also explain the high adherence rate, especially in an academic setting. Our HCWs may have more resources that allow them to participate in research activities. Barriers for adherence may have been the long study duration for HCWs with the need to remember swab collection and diary completion also during days off work and the efforts needed for patients to send the study materials back to the study office after discharge, in addition to differences in perceived importance of the need for full adherence to the protocol.

Our study has several strengths. In a well-defined study population within a single center, we were able to enroll and follow a substantial proportion of patients and HCWs over an entire influenza season. The critical proportion of participants, however, to detect influenza transmission events, has not been defined, and therefore a larger number of participants with higher adherence rates to the study protocol would certainly increase the probability of detecting influenza transmissions, especially from asymptomatic subjects. Nevertheless, incomplete data collection may still be adequate to address the question of detection of asymptomatic influenza transmission, as influenza virus shedding is expected to last for several days $[27,28]$. The best adherence to the protocol was observed in the first half of the study period, and as influenza activity is usually high during the first four to 6 weeks of an influenza season, the decline in adherence to the study protocol towards the end of the study period is of lower significance (https://www.bag.admin.ch/bag/de/home/krankheiten/ ausbrueche-epidemien-pandemien/aktuelle-ausbruecheepidemien/saisonale-grippe---lagebericht-schweiz.html). Nevertheless, the risk of missing transmission events during the later stage of the season may be higher.
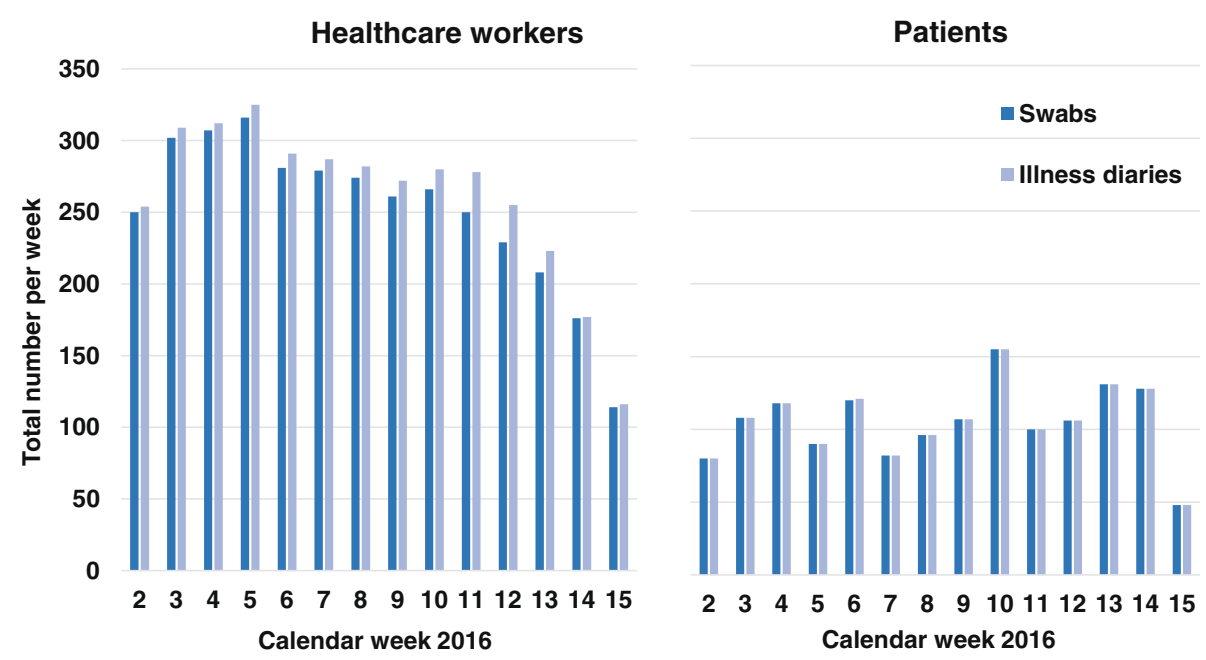

Fig. 1 Number of swabs and illness diaries collected in healthcare workers and patients per calendar week, influenza season 2015/16 
One limitation of our study is generalizability, as it was performed in specific wards and departments of a single university-affiliated institution in a high-income country. Our cohort of HCWs is relatively small and patients are diverse. It remains unclear whether the same recruitment rate and adherence can be observed in a different setting. We were not able to include all health care providers: our study population was limited to nurses, physicians and corporate hospitality staff working on the particular wards, and did not include other providers (e.g. physiotherapists, consulting physicians) who could also transmit influenza to study inpatients. In addition, we were unable to include visitors, who may also introduce influenza from the community.

\section{Conclusions}

In conclusion, our study provides proofs of concept that it is possible to follow a cohort of both patients and healthcare workers in an adult acute care hospital setting and perform intensive surveillance for respiratory infections. The question whether this proportion of HCWs and inpatients is sufficient to reliably detect transmission events, especially from asymptomatic participants, remains open and deserves further study. Based on our results, other investigators should be encouraged to perform similar studies in order to investigate real-world clinical questions about the transmission dynamics of influenza infection.

\section{Abbreviation}

HCW: Healthcare worker

\section{Acknowledgements}

Not applicable.

\section{Funding}

The TransFLUas influenza transmission study in acute healthcare is supported by the Swiss National Science Foundation (to Stefan P. Kuster and Alexandra Trkola; grant no. 32003B_156902) and the Swiss Federal Office of Public Health (to Stefan P. Kuster; Nr. 16.927730). The funding bodies had no role in the design of the study and collection, analysis, and interpretation of data and in writing the manuscript.

\section{Availability of data and materials}

The datasets generated and/or analysed during the current study are not yet publicly available due to ongoing analyses of the main study question, but will be available at a later stage from the corresponding author on reasonable request.

\section{Authors' contributions \\ Study concept and design: JB, RDK, TT, EB, MK, RM, HS2, HP, RW, AM, AT, SPK. Acquisition of data: HS1 and SPK. Statistical analysis: HS1 and SPK. Analysis and interpretation of data: HS1 and SPK. Drafting of the manuscript: HS1 and SPK. Critical revision of the manuscript for important intellectual content: HS1, $J B, R D K, T T, E B, M K, R M, H S 2, H P, R W, A M, A T, S P K$. All authors have read and approved the manuscript.}

\section{Ethics approval and consent to participate}

The research was conducted in accordance with the Declaration of Helsinki and national and institutional standards. The study protocol was reviewed and approved by the ethics committee of the Canton of Zurich (KEK-ZH-Nr:: 2015-0228). Written informed consent was obtained from all participants.
Consent for publication

Not applicable.

\section{Competing interests}

AM declares that she has received research funding paid to her institution from Hoffman LaRoche, GlaxoSmithKline, Sanofi-Pasteur. All other authors: no competing interests.

\section{Publisher's Note}

Springer Nature remains neutral with regard to jurisdictional claims in published maps and institutional affiliations.

\section{Author details}

'Division of Infectious Diseases and Hospital Epidemiology, University Hospital and University of Zurich, Raemistrasse 100 / HAL14 D6, 8091 Zürich, Switzerland. ${ }^{2}$ Institute of Medical Virology, University of Zurich, Zurich, Switzerland. ${ }^{3}$ Department of Internal Medicine, University Hospital and University of Zurich, Zurich, Switzerland. ${ }^{4}$ Pulmonary Division, University Hospital and University of Zurich, Zurich, Switzerland. ${ }^{5}$ Hematology, University Hospital and University of Zurich, Zurich, Switzerland. ${ }^{6}$ University Hospital Zurich, Zurich, Switzerland. ${ }^{7}$ Department of Microbiology, Sinai Health System, Toronto, Canada.

Received: 22 November 2018 Accepted: 1 May 2019

Published online: 21 May 2019

\section{References}

1. Bundesamt für Gesundheit. Saisonale Grippe 2011/2012: Zeit, sich impfen zu lassen. BAG Bulletin 2011;42:899-901.

2. Van Kerkhove MD, Vandemaele KA, Shinde V, Jaramillo-Gutierrez G, Koukounari A, Donnelly CA, Carlino LO, Owen R, Paterson B, Pelletier L, et al. Risk factors for severe outcomes following 2009 influenza a (H1N1) infection: a global pooled analysis. PLoS Med. 2011;8:e1001053.

3. Stevenson CG, McArthur MA, Naus M, Abraham E, McGeer AJ. Prevention of influenza and pneumococcal pneumonia in Canadian long-term care facilities: how are we doing? CMAJ. 2001;164:1413-9.

4. Collins AS. Preventing Health Care-Associated Infections. In: Hughes RG, editor. Patient Safety and Quality: An Evidence-Based Handbook for Nurses. Rockville (MD): Agency for Healthcare Research and Quality (US); 2008 Apr. Chapter 41. Available from: https://www.ncbi.nlm.nih.gov/books/NBK2683. Accessed 9 May 2019.

5. Horcajada JP, Pumarola T, Martínez JA, Tapias G, Bayas JM, de la Prada M, García F, Codina C, Gatell JM, Jiménez de Anta MT. A nosocomial outbreak of influenza during a period without influenza epidemic activity. Eur Respir J. 2003;21:303-7.

6. Voirin N, Barret B, Metzger MH. Vanhems P: hospital-acquired influenza: a synthesis using the outbreak reports and intervention studies of nosocomial infection (ORION) statement. J Hosp Infect. 2009;71:1-14.

7. Salgado CD, Farr BM, Hall KK, Hayden FG. Influenza in the acute hospital setting. Lancet Infect Dis. 2002;2:145-55.

8. Stott DJ, Kerr G, Carman WF. Nosocomial transmission of influenza. Occup Med (Lond). 2002;52:249-53.

9. Bell D, Nicoll A, Fukuda K, Horby P, Monto A, Hayden F, Wylks C, Sanders L, Van Tam J, Group WHOW. Non-pharmaceutical interventions for pandemic influenza, international measures. Emerg Infect Dis. 2006;12:81-7.

10. Eccles R. Asymptomatic spread of flu is not proved. BMJ. 2005;331:1145

11. Carrat F, Vergu E, Ferguson NM, Lemaitre M, Cauchemez S, Leach S, Valleron AJ. Time lines of infection and disease in human influenza: a review of volunteer challenge studies. Am J Epidemiol. 2008;167:775-85.

12. Jefferson T, Del Mar CB, Dooley L, Ferroni E, Al-Ansary LA, Bawazeer GA, van Driel ML, Nair S, Jones MA, Thorning S, Conly JM. Physical interventions to interrupt or reduce the spread of respiratory viruses. Cochrane Database Syst Rev. 2011;(7):CD006207. https://doi.org/10.1002/14651858.CD006207.pub4.

13. Fiore AE, Shay DK, Broder K, Iskander JK, Uyeki TM, Mootrey G, Bresee JS, Cox NS. Centers for disease C, prevention, advisory committee on immunization P: prevention and control of influenza: recommendations of the advisory committee on immunization practices (ACIP), 2008. MMWR Recomm Rep. 2008;57:1-60.

14. Akers IE, Weber R, Sax H, Boni J, Trkola A, Kuster SP. Influence of time to diagnosis of severe influenza on antibiotic use, length of stay, isolation 
precautions, and mortality: a retrospective study. Influenza Other Respir Viruses. 2017;11:337-44.

15. Statistik Kanton Zürich, 2015. Available from: www.statistik.zh.ch/internet/ justiz_inneres/statistik/de/themen/zhiz.html. Accessed 9 May 2019.

16. Charlson ME, Pompei P, Ales KL, Mackenzie CR. A new method of classifying prognostic comorbidity in longitudinal studies: development and validation. J Chronic Dis. 1987;40:373-83.

17. Heikkinen T, Salmi AA, Ruuskanen O. Comparative study of nasopharyngeal aspirate and nasal swab specimens for detection of influenza. BMJ. 2001; 322:138.

18. Larios OE, Coleman BL, Drews SJ, Mazzulli T, Borgundvaag B, Green K, Group ST-FS, McGeer AJ: Self-collected mid-turbinate swabs for the detection of respiratory viruses in adults with acute respiratory illnesses. PLoS One 2011, 6:e21335.

19. Smieja M, Castriciano S, Carruthers S, So G, Chong S, Luinstra K, Mahony JB, Petrich A, Chernesky M, Savarese M, Triva D. Development and evaluation of a flocked nasal midturbinate swab for self-collection in respiratory virus infection diagnostic testing. J Clin Microbiol. 2010;48:3340-2.

20. Fincham JE. Response rates and responsiveness for surveys, standards, and the journal. Am J Pharm Educ. 2008;72:43.

21. Ng S, Lopez R, Kuan G, Gresh L, Balmaseda A, Harris E, Gordon A. The timeline of influenza virus shedding in children and adults in a household transmission study of influenza in Managua, Nicaragua. Pediatr Infect Dis J. 2016:35:583-6.

22. Shiovitz TM, Bain EE, McCann DJ, Skolnick P, Laughren T, Hanina A, Burch D. Mitigating the effects of nonadherence in clinical trials. J Clin Pharmacol. 2016;56:1151-64.

23. Pfammatter AF, Mitsos A, Wang S, Hood SH, Spring B. Evaluating and improving recruitment and retention in an mHealth clinical trial: an example of iterating methods during a trial. Mhealth. 2017;3:49.

24. Frost R, McClurg D, Brady M, Williams B. Optimising the validity and completion of adherence diaries: a multiple case study and randomised crossover trial. Trials. 2016;17:489.

25. Chiffres-Clés des hôpiteaux suisses 2015. Office fédéral de la Santé publique, Berne, 2017, pp. 22-23, 348-349.

26. Access GBDH, Quality Collaborators. Electronic address cue, access GBDH, quality C: healthcare access and quality index based on mortality from causes amenable to personal health care in 195 countries and territories, 1990-2015: a novel analysis from the global burden of disease study 2015. Lancet 2017, 390:231-266.

27. Kwong JC. Editorial commentary: symptoms and viral shedding in naturally acquired influenza infections. Clin Infect Dis. 2016;62:438-9.

28. Lau LL, Cowling BJ, Fang VJ, Chan KH, Lau EH, Lipsitch M, Cheng CK, Houck PM, Uyeki TM, Peiris JS, Leung GM. Viral shedding and clinical illness in naturally acquired influenza virus infections. J Infect Dis. 2010;201:1509-16.

\section{Ready to submit your research? Choose BMC and benefit from:}

- fast, convenient online submission

- thorough peer review by experienced researchers in your field

- rapid publication on acceptance

- support for research data, including large and complex data types

- gold Open Access which fosters wider collaboration and increased citations

- maximum visibility for your research: over $100 \mathrm{M}$ website views per year

At BMC, research is always in progress.

Learn more biomedcentral.com/submissions 